\title{
Occurrence of No-Harm Incidents and Adverse Events in Hospitalized Patients with Ischemic Stroke or TIA: A Cohort Study Using Trigger Tool Methodology
}

\author{
Bartosch Nowak ${ }^{1}$, René Schwendimann ${ }^{2,3}{ }^{(D}$, Philippe Lyrer ${ }^{4}$, Leo H. Bonati ${ }^{4}$, Gian Marco De Marchis ${ }^{4}$, \\ Nils Peters ${ }^{4}$, Franziska Zúñiga ${ }^{3}\left(\mathbb{D}\right.$, Lili Saar ${ }^{5}$, Maria Unbeck ${ }^{6,7}$ (D) and Michael Simon ${ }^{3, *(D)}$
}

check for updates

Citation: Nowak, B.; Schwendimann, R.; Lyrer, P.; Bonati, L.H.; De Marchis, G.M.; Peters, N.; Zúñiga, F.; Saar, L.;

Unbeck, M.; Simon, M. Occurrence of No-Harm Incidents and Adverse Events in Hospitalized Patients with Ischemic Stroke or TIA: A Cohort Study Using Trigger Tool Methodology. Int. J. Environ. Res. Public Health 2022, 19, 2796. https://doi.org/10.3390/ ijerph19052796

Academic Editor: Paul B. Tchounwou

Received: 10 January 2022

Accepted: 24 February 2022

Published: 27 February 2022

Publisher's Note: MDPI stays neutral with regard to jurisdictional claims in published maps and institutional affiliations.

Copyright: (C) 2022 by the authors. Licensee MDPI, Basel, Switzerland. This article is an open access article distributed under the terms and conditions of the Creative Commons Attribution (CC BY) license (https:// creativecommons.org/licenses/by/ $4.0 /)$.
1 Department Head Organs, Spine- and Neuromedicine, University Hospital Basel, 4031 Basel, Switzerland; bartosch.nowak@usb.ch

2 Patient Safety Office, University Hospital Basel, 4031 Basel, Switzerland; rene.schwendimann@usb.ch

3 Institute of Nursing Science, University of Basel, 4031 Basel, Switzerland; franziska.zuniga@unibas.ch

4 Department of Neurology and Stroke Center, University Hospital and University of Basel, 4031 Basel, Switzerland; philippe.lyrer@usb.ch (P.L.); leo.bonati@usb.ch (L.H.B.); gian.demarchis@usb.ch (G.M.D.M.); nils.peters@usb.ch (N.P.)

5 Department of Neurology, Universitätsklinik Freiburg, 79106 Freiburg im Breisgau, Germany; lili.maria.saar@uniklinik-freiburg.de

6 School of Health and Welfare, Dalarna University, 79131 Falun, Sweden; mun@du.se

7 Department of Neurobiology, Care Sciences and Society, Karolinska Institutet, 17177 Stockholm, Sweden

* Correspondence: m.simon@unibas.ch; Tel.: +41-61-207-09-12

\begin{abstract}
Adverse events (AEs) — healthcare caused events leading to patient harm or even deathare common in healthcare. Although it is a frequently investigated topic, systematic knowledge on this phenomenon in stroke patients is limited. To determine cumulative incidence of no-harm incidents and AEs, including their severity and preventability, a cohort study using trigger tool methodology for retrospective record review was designed. The study was carried out in a stroke center at a university hospital in the German speaking part of Switzerland. Electronic records from 150 randomly selected patient admissions for transient ischemic attack (TIA) or ischemic stroke, with or without acute recanalization therapy, were used. In total, 170 events (108 AEs and 62 no-harm incidents) were identified, affecting 83 patients (55.3\%; 95\% CI 47 to 63.4 ), corresponding to an event rate of 113 events / 100 admissions or 142 events/1000 patient days. The three most frequent AEs were ischemic strokes $(n=12,7.1 \%)$, urinary tract infections $(n=11,6.5 \%)$ and phlebitis $(n=10$, $5.9 \%)$. The most frequent no-harm incidents were medication events ( $n=37,21.8 \%)$. Preventability ranged from $12.5 \%$ for allergic reactions to $100 \%$ for medication events and pressure ulcers. Most of the events found (142; 83.5\%; $95 \%$ CI 76.9 to 88.6) occurred throughout the whole stroke care. The remaining 28 events ( $16.5 \%$; $95 \%$ CI 11.4 to 23.1 ) were detected during stroke care but were related to care outside the stroke pathway. Trigger tool methodology allows detection of AEs and no-harm incidents, showing a frequent occurrence of both event types in stroke and TIA patients. Further investigations into events' relationships with organizational systems and processes will be needed, first to achieve a better understanding of these events' underlying mechanisms and risk factors, then to determine efforts needed to improve patient safety.
\end{abstract}

Keywords: adverse events; no-harm incidents; retrospective record review; stroke; trigger tool methodology

\section{Introduction}

Adverse events (AEs) commonly cause patients temporary or permanent disability [1,2], or even death. Other consequences include extended hospital stay length [3,4] and increased healthcare costs [5]. AEs are caused by care providers and have no direct relationship to the patient's underlying condition [6]. In general, roughly one patient in ten is affected 
by an AE during in-hospital treatment [1,2]. Although AEs are a frequently investigated topic in healthcare [1,2], little is known about their occurrence in stroke patients. While few studies have investigated this phenomenon in stroke services $[3,7,8]$, those that have reported a wide range of $\mathrm{AE}$ incidence: from $2.8 \%$ [8] to $63 \%$ [3], with up to $47 \%$ [7] considered preventable. Infections [4], hospital-acquired thromboembolism, strokes during interventional procedures, falls [7] and AEs resulting from recombinant tissue plasminogen activator (rtPA) administration, such as bleeding, are among the most common. And among rtPA-related AEs, intra-cerebral hemorrhage is the most serious [8]. These studies, focusing on stroke patients, used different methods for event detection, such as Global Trigger Tool (GTT) methodology [8], voluntary and mandatory reporting systems [7] and retrospective record review [3].

Based on modern patient safety concepts, positive and negative outcomes can occur form the same system $[9,10]$. It is likely that no-harm incidents (those that reached the patient but caused no discernable harm) [11] have the same contributing factors as AEs. The main difference is that, in these cases, patients were not harmed. Putting an additional focus on no-harm incidents provides valuable information on areas for improvement and learning from how to anticipate and reduce emerging risks before patient harm occurs. Investigating AEs and no-harm incidents is important to gain knowledge and understanding of how to improve patient safety [12]. Therefore, the information on no-harm incidents provides an additional perspective on patient safety during care services and the opportunity to improve areas at risk for patient harm [13].

A well-known and established method for the detection of events is that of retrospective record reviews, using trigger tool methodology [13-15]. One commonly used tool is the Global Trigger Tool (GTT) [6]. Using routinely collected care data from the patient's record, the GTT review process is carried out by a review team in two stages. The primary reviewers, who need to be familiar with both the local documentation structure and with the screened population's clinical background, conduct the first review independently. This involves screening each record for predefined triggers, which may hint at potential events. If triggers are found, the record is searched in more detail for potential events. If an event is detected, a severity rating is performed, and a consensus reached between the primary reviewers. In a second review stage, the consensus is presented to a physician for result verification [6]. Compared to voluntary reporting systems, this stage's main advantage is its substantially higher sensitivity, regarding event detection [14].

The GTT consists of six trigger modules (e.g., care module, medication module). In some studies, all of these modules are used [16,17], while most researchers use only those modules relevant to their clinical setting $[18,19]$. However, other users of the GTT methodology design additional modules (e.g., oncology module $[20,21]$ ) or create modified versions, tailored specifically to their clinical context $[8,15,22]$. While some versions diverge too much from the original GTT to label it as GTT, they are still considered as trigger tools (TTs). Even though TT methodology usually focuses on the detection of AEs [6], it is also possible to identify no-harm incidents during the same retrospective record review process $[13,23,24]$. We, therefore, assume that during stroke services, it is possible to identify both no-harm incidents and AEs, using TT methodology.

Working with a randomly selected sample of in-hospital patients treated for ischemic stroke or transitory ischemic attack (TIA), in a Swiss stroke center, this study's purpose was to determine cumulative incidence of no-harm incidents and AEs, including their severity and preventability.

\section{Materials and Methods}

\subsection{Study Design}

We conducted a retrospective cohort study following TT methodology for the review of routinely collected patient data from electronic healthcare records (EHRs) [6]. 


\subsection{Setting and Sample}

The study was conducted in a certified stroke center integrated in a 770-bed university hospital in the German-speaking part of Switzerland. For the acute phase, patients usually stay 24-72 $\mathrm{h}$ in the stroke unit before being transferred to the neurological ward. The entire stoke response pathway, which includes the patient's admission, in-hospital treatment, care and diagnostics regarding stroke, will henceforth be called stroke service. Our review included a screening of the full EHR data for each admitted patient. Due to similar pathogenic causes and treatment options, this study focused on patients with ischemic stroke or TIA. Patients who had provided general consent were aged 18 years or older, presented with TIA or ischemic stroke, who were admitted between 1 April 2017 and 31 March 2018 to the stroke center, with or without acute recanalization therapy and an in-hospital stay of at least $24 \mathrm{~h}$, were eligible for this study. Patients with hemorrhagic stroke were excluded. During the study period, 1090 patients (hemorrhagic stroke $n=82$, any kind of ischemic stroke $n=885$, TIA $n=123$ ) were admitted to the stroke center. For this study, 424 patients met the inclusion criteria and therefore were eligible for the random sampling. Due to resource constraints, a sample size of 150 EHRs was drawn by B.N. using $R$ statistical software [25]. No formal power analysis was conducted for this study. Based on an AE rate of approximately $10 \%$ [1,2] and a sample size of $n 150$, a 95\% confidence interval of 3.4-12.2 was expected.

\subsection{Definitions}

An AE is "unintended physical injury resulting from or contributed to by medical care that requires additional monitoring, treatment or hospitalization, or that results in death" [6]. No-harm incidents are events that reached the patient but caused no discernible harm [11]. A preventable event was defined as one that could have been prevented if adequate actions had been taken during the patient's contact with healthcare [26].

\subsection{Measurement and Variables}

Events were detected using 36 triggers, i.e., specific hints that commonly indicate AEs. The triggers used were based on the GTT's 15-trigger care module (e.g., fall) and its 13-trigger medication module (e.g., vitamin $\mathrm{K}$ administration) [6] and were enriched with eight self-developed stroke-specific triggers (e.g., endovascular treatment). These triggers were based on potential events in connection to stroke treatment and used stroke triggers from the literature [8] after discussion with the research team and senior stroke physicians. Our targets included events arising from acts both of commission (active care delivery) and of omission.

When a potential event was found via the triggers, a four-point Likert-type scale was used to determine whether or not it was care-related ( $1=$ not related to care, $2=$ probably not related to care, $3=$ probably related to care, $4=$ related to care). If the event was judged as 3 or 4 , the reviewer continued the review process. To gauge preventability, a similar four-point Likert-type scale was used ( 1 = not preventable, 2 = probably not preventable, 3 = probably preventable, $4=$ preventable). This rating was dichotomized into either not preventable ( 1 and 2 ) or preventable ( 3 and 4) [27]. To determine severity, a modified version of the recommended National Coordinating Council for Medication Error Reporting and Prevention (NCC MERP) Index was applied [6,27,28]. This scale consists of nine categories lettered A-I. Categories A and B indicate respectively potential errors and errors that never reached the patient; $C$ and D indicate no-harm incidents; category E-I are considered AEs. Events categorized as C to I were included in this study. To represent a broad patient perspective, we collected all events, independent of their origin.

Patient demographics were manually extracted from the EHR by B.N. Length of stay (LOS) and the modified Rankin Scale (mRS) data were retrieved from the stroke center's data in the Swiss Stroke Registry [29]. The mRS is a seven-level scale that gauges functional outcomes after stroke (range: no symptoms-dead) [30,31]. National Institutes of Health 
Stroke Scale (NIHSS) ratings were extracted from routinely collected data during the review process.

\subsection{Data Collection}

From January 2019 to March 2019, two trained registered nurse reviewers with clinical backgrounds in stroke care and knowledge of the EHR structure (B.N. and L.S.) independently reviewed case records for each selected patient's inpatient stay during the sample period (see Supplementary Materials). As a first step, all nurse, physician and therapist EHR documentation related to the selected admissions was systematically checked for occurrences of the predefined triggers. To allow a thorough baseline review, the time for primary review was not limited. Each reviewer recorded their findings in a self-developed study-specific protocol. In case of positive triggers, the EHR was searched in more detail to detect information about the potential event. If a potential event was identified, the primary reviewer evaluated whether it was care-related. This step was adopted from another TT study [24]. If an event was care-related, its severity rating, preventability determination, and type were set. Both reviewers met regularly to discuss and find consensus on the collected data. In the second review stage, B.N. presented the findings from the screening protocol to a senior stroke physician to verify the results. In cases of uncertainty or open questions, the patient record review was repeated until a consensus was reached.

\subsection{Data Analysis}

Descriptive statistics, e.g., frequencies, events per 100 admissions and per 1000 patient days, mean, standard deviation (SD), t-test for continuous and chi-squared test for categorical variables and 95\% CI were compiled and analyzed. For result calculation, statistical software R, version 3.5.1 [25] and Microsoft Excel, 365 ProPlus (version 2010) [32] were used.

The positive predictive value (PPV) was calculated for each trigger and for this study refers to the number of times triggers have led to a specific $\mathrm{AE}$ or no-harm incident, divided by the overall number of times this particular trigger was found [22]. An overview of all triggers can be found in the Supplementary Materials, Table S1.

\section{Results}

The study sample consisted of 150 inpatients (110 males (73.3\%)); overall mean LOS 8 days $(\mathrm{SD}=5.5)$. In 135 patients $(90 \%)$, the reason for admission was a cerebral ischemic infarction. As acute treatment, 32 patients $(21.3 \%)$ received systemic rtPA, EVT or a combination of both. The mean NIHSS score on admission was $3.8(\mathrm{SD}=4.3)$. Patients affected by an AE $(n=64)$ stayed 3.5 days $(p=<0.001)$ longer in the hospital, had a more severe stroke (mean NIHSS 5.8, $\mathrm{SD}=5.2, p=0.009$ ) and received acute revascularization therapy more often $(p=0.001)$. More details are displayed in Table 1 .

\subsection{Identified Events}

We identified 170 events, of which 62 (36.5\%) were no-harm incidents involving 43 patients; the remaining 108 (63.5\%) were AEs, affecting 64 patients. In total, 83 (55.3\%) patients were affected by both types of events, with an overall event occurrence of 113 events per 100 admissions, and 142 events per 1000 patient days, respectively.

Of the total events, $110(64.7 \%)$ were judged as preventable. Of those, 51 were no-harm incidents, involving 36 patients; the remaining 59 were AEs, affecting 41 patients. Overall, 61 patients were affected by preventable events, with a preventable occurrence rate of 73 events per 100 patients and 93 events per 1000 patient days. More details are presented in Table 2. 
Table 1. Demographics and clinical characteristics.

\begin{tabular}{|c|c|c|c|c|}
\hline Demographic and Clinical Categories & Frequency & Patients with No AE $n=86$ & Patients with AE $n=64$ & $p$-Value \\
\hline Age in years, mean $(\mathrm{SD})^{1}$ & $71.8(13.3)$ & $72.1(12.5)$ & $71.4(14.5)$ & 0.756 \\
\hline \multicolumn{5}{|l|}{ Sex } \\
\hline Men, $n(\%)$ & $110(73.3)$ & $70(81.4)$ & $40(62.5)$ & 0.016 \\
\hline Female, $n(\%)$ & $40(26.7)$ & $16(18.6)$ & $24(37.5)$ & \\
\hline \multicolumn{5}{|l|}{$\operatorname{LOS}^{2}$} \\
\hline Patient days, mean (SD) & $8.0(5.5)$ & $6.5(4.8)$ & $10.0(5.8)$ & $<0.001$ \\
\hline Patient days, total & 1192 & & & \\
\hline Cerebrovascular events, $n(\%)$ & & & & 0.062 \\
\hline Ischemic stroke & $135(90)$ & $85(98.8)$ & $64(100)$ & \\
\hline TIA $^{3}$ & $15(10)$ & $1(1.2)$ & $0(0.0)$ & \\
\hline Acute treatment, $n(\%)$ & & & & 0.001 \\
\hline Conservative & $118(78.7)$ & $75(87.2)$ & $43(67.2)$ & \\
\hline Systemic rtPA ${ }^{4}$ & $22(14.7)$ & $11(12.8)$ & $11(17.2)$ & \\
\hline EVT $^{5}$ & $6(4.0)$ & $0(0.0)$ & $6(9.4)$ & \\
\hline rtPA and EVT & $4(2.7)$ & $0(0.0)$ & $4(6.2)$ & \\
\hline \multicolumn{5}{|l|}{ Clinical metrics } \\
\hline NIHSS ${ }^{6}$ on admission, mean (SD) & $3.8(4.3)$ & $2.3(2.4)$ & $5.8(5.2)$ & 0.009 \\
\hline mRS $^{7}$ after 3 months, mean (SD) & $1.3(1.4)$ & $1.1(1.4)$ & $1.6(1.5)$ & 0.201 \\
\hline
\end{tabular}

Abbreviations: ${ }^{1}$ standard deviation, ${ }^{2}$ LOS length of stay, ${ }^{3}$ TIA transitory ischemic attack, ${ }^{4}$ rtPA recombinant tissue plasminogenactivator, ${ }^{5}$ EVT endovascular treatment, ${ }^{6}$ NIHSS National Institution of Health Stroke Scale $(0-42),{ }^{7}$ mRS modified Rankin Scale (0-6).

Table 2. Overview of no-harm incidents and AE occurrence.

\begin{tabular}{|c|c|c|c|}
\hline & No-Harm Incidents & AEs $^{1}$ & Total \\
\hline \multicolumn{4}{|l|}{ Event overview } \\
\hline No ${ }^{2}$ of events & 62 & 108 & 170 \\
\hline No of affected patients, $n(\% ; 95 \%$ CI $)$ & $43(28.7 ; 21.7-36.7)$ & $64(42.7 ; 34.7-51.0)$ & $83(55.3 ; 47-63.4)$ \\
\hline No of patients with $>1$ event $(\%)$ & $12(8.0)$ & $\begin{array}{c}27(18.0) \\
27(1.0)\end{array}$ & $\begin{array}{c}39(26.0) \\
39(26)\end{array}$ \\
\hline No of events per 100 admissions & $\begin{array}{l}12(0.0) \\
41\end{array}$ & $\begin{array}{l}27 \\
72\end{array}$ & 113 \\
\hline No of events per 1000 patient days & 52 & 90 & 142 \\
\hline \multicolumn{4}{|l|}{ Preventable events } \\
\hline No of preventable events & 51 & 59 & 110 \\
\hline No of affected patients, $n(\% ; 95 \% \mathrm{CI})$ & $36(24.0 ; 17.6-31.8)$ & $41(27.3 ; 20.5-35.3)$ & $61(40.7 ; 32.8-49)$ \\
\hline No of patients with $>1$ preventable event $(\%)$ & $10(6.7)$ & $11(7.3)$ & $21(14)$ \\
\hline No of preventable events per 100 admissions & 34 & 39 & 73 \\
\hline No of preventable events per 1000 patient days & 43 & 50 & 93 \\
\hline
\end{tabular}

Abbreviations: ${ }^{1}$ AE adverse event, ${ }^{2}$ No number.

\subsection{Detailed Event Presentation}

Of the 170 identified events, $46(27.1 \%)$ were related to general care. The two most common events within this category were phlebitis $(n=10,5.9 \%)$ and constipation lasting five days or longer $(n=7,4.1 \%)$. We also detected $37(21.8 \%)$ medication events, for example, wrong prescriptions, which were the most frequent no-harm incidents. Bleeding (various types) occurred eleven times (6.5\%). These included three (1.8\%) instances of epistaxis and two $(1.2 \%)$ of gastrointestinal bleeding. Neurological events appeared $30(17.6 \%)$ times, including $12(7.1 \%)$ cases of ischemic stroke, of which three $(1.8 \%)$ were ischemic re-strokes and nine $(5.3 \%)$ were new strokes. These 12 strokes included small cortical infarctions without clinical impact, as well as severe strokes that led to permanent disability. We also identified three $(1.8 \%)$ cases of intracerebral bleeding, as a complication of rtPA administration. Within the category of healthcare-associated infections, urinary tract infections were the most frequent $\mathrm{AE}$, with eleven (6.5\%) events. Of the eleven internal events, statin induced myalgia / myopathy accounted for three (1.8\%). Of eight $(4.7 \%)$ allergic reactions, rashes appeared in five $(2.9 \%)$. Eight falls $(4.7 \%)$ were identified, five $(2.9 \%)$ without injury, three $(1.8 \%)$ with local contusions. Four $(2.4 \%)$ category I pressure ulcers were found $(2.4 \%)$. 
An overview of the occurred event types can be found in Table 3. The full table is presented in the Supplementary Materials, Table S2, as well as data regarding interrater reliability, screening time and trigger outcomes.

Table 3. Event types.

\begin{tabular}{|c|c|c|c|}
\hline & $\begin{array}{c}\text { No-Harm Incidents, } \\
n(\% ; 95 \% \text { CI })\end{array}$ & $\begin{array}{c}\text { AEs }{ }^{1} \\
n(\% ; 95 \% \text { CI })\end{array}$ & $\begin{array}{c}\text { Total, } \\
n(\% ; 95 \% \text { CI })\end{array}$ \\
\hline General care related events & $17(10 ; 6.1-15.8)$ & $29(17.1 ; 11.9-23.7)$ & $46(27.1 ; 20.7-34.5)$ \\
\hline Medication events & $37(21.8 ; 16-28.9)$ & - & $37(21.8 ; 16.0-28.9)$ \\
\hline Neurologic events & $1(0.6 ; 0.03-3.7)$ & $29(17.1 ; 11.9-23.7)$ & $30(17.6 ; 12.4-24.4)$ \\
\hline Healthcare-associated infections & - & $15(8.8 ; 5.2-14.4)$ & $15(8.8 ; 5.2-14.4)$ \\
\hline Bleedings & - & $11(6.5 ; 3.4-11.6)$ & $11(6.5 ; 3.4-11.6)$ \\
\hline Internal events & $1(0.6 ; 0.03-3.7)$ & $10(5.9 ; 3.0-10.8)$ & $11(6.5 ; 3.4-11.6)$ \\
\hline Allergic reactions & - & $8(4.7 ; 2.2-9.4)$ & $8(4.7 ; 2.2-9.4)$ \\
\hline Falls & $6(3.5 ; 1.4-7.9)$ & $2(1.1 ; 0.2-4.6)$ & $8(4.7 ; 2.2-9.4)$ \\
\hline Pressure ulcers, category I & - & $4(2.4 ; 0.8-6.3)$ & $4(2.4 ; 0.8-6.3)$ \\
\hline Total, $n(\%)$ & $62(36.5)$ & $108(63.5)$ & $170(100)$ \\
\hline
\end{tabular}

Abbreviations: ${ }^{1} \mathrm{AE}$ adverse event.

\subsection{Severity Rating and Preventability}

Accounting for $36.5 \%(n=52)$ of all events, no-harm incidents are represented on the NCC MERP index, in categories C and D. Temporary patient harm, with or without prolonged hospitalization or outpatient treatment (category $\mathrm{E}$ and $\mathrm{F}$ ), was found in $54.1 \%$ $(n=92)$ of all events. In $8.8 \%(n=15)$ of cases, patients suffered permanent harm due to ischemic stroke, brain parenchymal bleeding or epilepsies (category G). One patient suffered life-threatening gastrointestinal bleeding (category $\mathrm{H}$ ). No patient deaths were found during the review process.

The preventability ranged broadly (12.5-100\%) between event categories. For example, while all medication events and pressure ulcers were considered preventable, healthcareassociated infections and general care-related events were rated as preventable in $80 \%$ and $78.3 \%$ of the cases, respectively. Allergic reactions and internal events showed the lowest preventability rates: respectively, $12.5 \%$ and $27.3 \%$.

Most of the found events $(142,83.5 \%)$ occurred during the stroke care of the initial stroke admission. The origin of these events was in direct relation to stroke care. The remaining $28(16.5 \%)$ events were found during the review, but the origin of these events was related to other care services, outside the stroke care (Table 4).

Table 4. Severity rating, preventability, and relation to stroke service.

\begin{tabular}{|c|c|c|c|c|c|c|c|c|c|}
\hline \multirow{3}{*}{ Event Category } & \multicolumn{7}{|c|}{ Severity Rating NCC MERP ${ }^{1}$ Index } & \multirow{2}{*}{$\begin{array}{c}\text { Preventability } \\
\text { Preventable } \\
\text { Events }\end{array}$} & \multirow{2}{*}{$\begin{array}{l}\text { Stroke } \\
\text { Service } \\
\text { Relation }\end{array}$} \\
\hline & C & D & $\mathbf{E}$ & $\mathbf{F}$ & G & $\mathbf{H}$ & I & & \\
\hline & $n(\%)$ & $n(\%)$ & $n(\%)$ & $n(\%)$ & $n(\%)$ & $n(\%)$ & $n(\%)$ & $n(\%)$ & $n(\%)$ \\
\hline $\begin{array}{l}\text { General care-related } \\
\text { events }\end{array}$ & $9(19.6)$ & $8(17.4)$ & $26(56.5)$ & $3(6.5)$ & - & - & - & $36(78.3)$ & $38(82.6)$ \\
\hline Medication events & $35(94.6)$ & $2(5.4)$ & - & - & - & - & - & 37 (100) & $35(94.6)$ \\
\hline Neurologic events & - & $1(3.3)$ & $8(26.7)$ & $6(20.0)$ & $15(50.0)$ & - & - & $10(33.3)$ & $23(76.7)$ \\
\hline $\begin{array}{l}\text { Healthcare-associated } \\
\text { infections }\end{array}$ & - & - & $12(80.0)$ & $3(20.0)$ & - & - & - & $12(80.0)$ & $11(73.3)$ \\
\hline Bleedings & - & - & $8(72.7)$ & $2(18.2)$ & - & $1(9.1)$ & - & $4(36.4)$ & $9(81.8)$ \\
\hline Internal events & - & $1(9.1)$ & $8(72.7)$ & $2(18.2)$ & - & - & - & $3(27.3)$ & $10(90.9)$ \\
\hline Allergic reactions & - & - & $7(87.5)$ & $1(12.5)$ & - & - & - & $1(12.5)$ & $7(87.5)$ \\
\hline Falls & $1(12.5)$ & $5(62.5)$ & $2(25.0)$ & - & - & - & - & $3(37.5)$ & $6(75.0)$ \\
\hline $\begin{array}{l}\text { Pressure ulcers, } \\
\text { category } \mathrm{I}^{\circ}\end{array}$ & - & - & $4(100)$ & - & - & - & - & $4(100)$ & $3(75.0)$ \\
\hline Total & $45(26.5)$ & $17(10)$ & $75(44.1)$ & $17(10)$ & $15(8.8)$ & $1(0.6)$ & - & $110(64.7)$ & $142(83.5)$ \\
\hline
\end{tabular}

Abbreviations: ${ }^{1}$ NCC MERP National Coordinating Council for Medication Error Reporting and Prevention, $C$ an error that reached the patient but did not cause harm, D an error that reached the patient and required monitoring or intervention to confirm that it resulted in no harm to the patient, E temporary harm to the patient, F temporary harm to the patient and required initial or prolonged hospitalization or out-patient treatment, G permanent patient harm, $\mathrm{H}$ intervention required to sustain life, I patient death. 


\subsection{Trigger Occurrence and Positive Predictive Value on Appended Stroke Triggers}

The stroke-specific triggers were identified 106 times during primary review, leading to a total PPV of $14.2 \%$. Fourteen times, four triggers indicated the occurrence of twelve AEs (parenchymal bleeding, epistaxis, other allergic reactions, new stroke and re-stroke, other cerebrovascular events and gingival bleeding). Three triggers were identified but were assessed not to be related to any no-harm incident or AE. One trigger was not identified (Table 5). A detailed presentation of all triggers can be found in the Supplementary Materials.

Table 5. Appended stroke module with frequency of trigger occurrence and positive predictive value.

\begin{tabular}{|c|c|c|c|c|c|c|}
\hline Stroke Trigger Module & $\begin{array}{c}\text { No }{ }^{1} \text { of } \\
\text { Triggers } \\
\text { Detected in } \\
\text { Primary } \\
\text { Review }\end{array}$ & $\begin{array}{l}\text { No of } \\
\text { Triggers } \\
\text { Related to } \\
\text { AE }^{2}\end{array}$ & $\begin{array}{l}\text { PPV }^{3} \text { for } \\
\text { Triggers } \\
\text { Related to } \\
\text { AE, \% }\end{array}$ & $\begin{array}{c}\text { No of } \\
\text { Triggers } \\
\text { Related to } \\
\text { No-Harm } \\
\text { Incidents }\end{array}$ & $\begin{array}{c}\text { PPV of } \\
\text { Triggers } \\
\text { Related to } \\
\text { No-Harm } \\
\text { Incidents, \% }\end{array}$ & $\begin{array}{c}\text { PPV } \\
\text { Total, \% }\end{array}$ \\
\hline $\mathrm{EVT}^{4}$ & 20 & 6 & 30.0 & 1 & 5.0 & 35.0 \\
\hline $\begin{array}{l}\text { Neurological decline of the } \\
\text { GCS }{ }^{5} \geq 4 \text { from the intimal score }\end{array}$ & 4 & 1 & 25.0 & 0 & 0 & 25.0 \\
\hline Systemic administration of rtPA ${ }^{6}$ & 27 & 5 & 18.5 & 0 & 0 & 18.5 \\
\hline $\begin{array}{l}\text { Neurological decline of the } \\
\text { NIHSS }{ }^{7} \geq 4 \text { from the initial score }\end{array}$ & 19 & 2 & 10.5 & 0 & 0 & 10.5 \\
\hline $\begin{array}{l}\text { Thrombin time } 1 \leq 120 \text { s and } \\
\text { thrombin time } 2 \leq 4-8 \mathrm{~s} \text { while } \\
\text { under therapeutic heparin within } \\
24 \mathrm{~h} \text { from onset }\end{array}$ & 32 & 0 & 0 & 0 & 0 & 0 \\
\hline $\begin{array}{l}\text { Systolic blood pressure above } \\
185 \mathrm{mmHg}^{8} \text { during rtPA } \\
\text { administration or in accordance } \\
\text { with the neuroradiological report }\end{array}$ & 3 & 0 & 0 & 0 & 0 & 0 \\
\hline $\begin{array}{l}\text { Computer tomography brain } \\
\text { scan } \leq 12 \mathrm{~h} \text { after } \\
\text { rtPA administration }\end{array}$ & 1 & 0 & 0 & 0 & 0 & 0 \\
\hline $\begin{array}{l}\text { Administration of } \\
\text { coagulation factors }\end{array}$ & 0 & 0 & 0 & 0 & 0 & 0 \\
\hline Total & 106 & 14 & 13.2 & 1 & 0.9 & 14.2 \\
\hline
\end{tabular}

\section{Discussion}

Using retrospective record reviews, following GTT methodology [6], we conducted a retrospective cohort study on no-harm incidents' and AEs' occurrence of 150 randomly selected patients, treated for ischemic stroke or TIA. We found 170 events relating to 83 patients $(55.3 \%)$

Very few studies report results on AE occurrence in stroke patients; among those that do, the variation in results is very wide $[3,7,8]$. Studies from stroke care settings with a similar focus range from $2.8-63 \%$ for AEs $[3,7,8]$. This reflects their wide range of clinical settings (e.g., emergency departments), patient samples (e.g., patients with cerebral bleeding), detection methods (e.g., voluntary reporting systems) and even definitions of AEs, all of which limit direct comparison of results. However, regardless of the setting, sample, or detection methods, one finding is consistent: care-related events that can or do harm stroke patients are common.

Preventable events were found among both AEs and no-harm incidents. Of 108 AEs detected, just over half (54.6\%) were deemed preventable. Of the three most common 
preventable event categories, two-medication events and pressure ulcers (category I) —are both $100 \%$ preventable, while the third ranked category, healthcare-associated infections, are $80 \%$ preventable. Regarding stroke service-related no-harm incidents and AEs, we classed $65.5 \%$ of cases as preventable. This number is high compared to another university hospital with an integrated stroke service, which judged $47 \%$ of found events preventable [7]. Although preventability was determined via different methods, both sets of findings indicate a strong potential to adapt care systems to prevent patients from harm. Taking a range of care setting characteristics into account, one systematic review and meta-analysis identified a preventability rate of 55\% [33]. The next step is to analyze each event type separately, focusing on its mechanisms of occurrence and contributing factors.

Our modified version of the TT allows a more inclusive review of events to maximize our data's value. It includes the capacity to detect and evaluate acts, both of commission and of omission. In fact, our comprehensive review, theoretically, could detect virtually any possible event documented in the EHR. No time limit applied to the primary review and both no-harm incidents and AEs were collected. All events were classified according to the NCC MERP index classifications. Even if not specifically recommended by the GTT white paper [6], we additionally gauged each event's preventability. These adaptions likely increased our review method's sensitivity, explaining our higher-than-usual incidence rate. We also created a stroke-specific module to detect AEs, such as bleedings or any neurovascular events, due to stroke-specific treatments. However, adding eight strokespecific triggers to the original TT likely didn't increase the chance of higher event detection rate. Four stroke-specific triggers (systemic administration of rtPA, EVT, neurologic decline of the NIHSS $\geq 4$ from the initial score and neurologic decline of the GCS $\geq 4$ from the initial score) identified twelve AEs, such as parenchymal bleeding, epistaxis, other allergic reactions, new stroke and re-stroke, other cerebrovascular events, and gingival bleeding. All of these could have been identified by other triggers, such as any procedure complications or in-hospital stroke. A comparison of record reviews with two teams, one using the original GTT modules, the other using an additional oncology module, showed no significant differences on the rate of found events [20]. Even though we do not have a direct comparison, the low PPV of $14.2 \%$ of the total stroke appended triggers supports our assumption, that no additional value was made.

Customizing the GTT is common practice. In general, modifying the GTT includes the AE definition, the number of reviewers, sample size, harm severity ratings, including events related to omission, preventability judgment, and method of reporting AE rates [15]. The one previous study to use GTT methodology in stroke patients customized the tool to identify specific AEs within the first $24 \mathrm{~h}$ after rtPA administration. In that case, only 14 AEs were found in 498 patients. Rather than classifying harm severity for every AE using the NCC MERP index, only intra-cerebral bleedings received classification (via the intracerebral hemorrhage scale) [8,34]. One of the GTT's strengths is that it can be customized to make it either more inclusive or more exclusive for event detection. To facilitate the provision of robust data, particularly for further investigations into issues affecting patient safety, we recommend tailoring the GTT as necessary to the targeted clinical setting.

\section{Strengths and Limitations}

For the first time, this study used TT methodology to detect no-harm incidents and AEs, including acts both of commission and of omission, in TIA and stroke patients [6]. Each record was double-reviewed with the consensus data, then subjected to analyses. Furthermore, any detected event was classified regarding its severity using the NCC MERP index, and its preventability determined. This baseline determination provides robust results for further investigation and international comparison. The collection of no-harm incidents and AEs identified risk areas for further improvement, to avoid or mitigate patient harm.

This first explorative pilot study also has certain limitations. Most notably, it was a single center study, using a relatively small sample of 150 admissions. Furthermore, we 
applied descriptive statistics to present epidemiological data and did not correct for specific patient characteristics and conditions that might increase the likelihood of event occurrence. In addition, our record review methodologies rely entirely on events documented in the records. Therefore, comprehensive event detection is dependent on proper and complete documentation. If iatrogenic events are not recorded, they cannot be detected [35].

\section{Conclusions}

Retrospective record reviews, using TT methodology, was perceived as a sensitive system of detecting both AEs and no-harm incidents during stroke service. Although the results may not be generalized to other stroke centers, they highlight the high frequency of events that affect patient safety in stroke care. Both to improve our understanding of such events' underlying mechanisms and to support interventions and precautions, to tackle the related phenomena, we recommend further investigation into their relationships with organizational processes and structures.

Supplementary Materials: The following supporting information can be downloaded at: https: / / www.mdpi.com/article/10.3390/ijerph19052796/s1, Table S1. Frequency of trigger occurrence and positive predictive value, sorted by the column PPV total; Table S2. Detailed event presentation; sorted by column total. References $[12,22,24,36,37]$ are cited in the supplementary materials

Author Contributions: Conceptualization, B.N., M.S., R.S., M.U. and F.Z.; methodology, B.N., M.S., R.S. and M.U.; formal analysis, B.N.; investigation, B.N., L.S., P.L., L.H.B., G.M.D.M. and N.P.; writing-original draft preparation, B.N.; writing-review and editing, B.N., M.S., R.S., M.U., L.S., F.Z., P.L., L.H.B., G.M.D.M. and N.P.; supervision, M.U. All authors have read and agreed to the published version of the manuscript.

Funding: This research received no external funding.

Institutional Review Board Statement: Ethical approval for this study was obtained from the ethics committee of Nordwest, and Zentralschweiz approved this study (REC number: 2018-01560).

Informed Consent Statement: Informed consent was obtained from all subjects involved in the study.

Data Availability Statement: The data presented in this study are available on request from the corresponding author.

Conflicts of Interest: The authors declare no conflict of interest.

\section{References}

1. Schwendimann, R.; Blatter, C.; Dhaini, S.; Simon, M.; Ausserhofer, D. The occurrence, types, consequences and preventability of in-hospital adverse events-a scoping review. BMC Health Serv. Res. 2018, 18, 521. [CrossRef]

2. de Vries, E.N.; Ramrattan, M.A.; Smorenburg, S.M.; Gouma, D.J.; Boermeester, M.A. The incidence and nature of in-hospital adverse events: A systematic review. Qual. Saf. Health Care 2008, 17, 216-223. [CrossRef]

3. Daud-Gallotti, R.; Dutilh Novaes, H.M.; Lorenzi, M.C.; Eluf-Neto, J.; Namie Okamura, M.; Tadeu Velasco, I. Adverse events and death in stroke patients admitted to the emergency department of a tertiary university hospital. Eur. J. Emerg. Med. 2005, 12, 63-71. [CrossRef]

4. Sauro, K.M.; Quan, H.; Sikdar, K.C.; Faris, P.; Jette, N. Hospital safety among neurologic patients: A population-based cohort study of adverse events. Neurology 2017, 89, 284-290. [CrossRef]

5. Slawomirski, L.; Auraaen, A.; Klazinga, N.S. The Economics of Patient Safety; OECD: Paris, France, 2017. [CrossRef]

6. Griffin, F.A.; Raser, R.K. IHI Global Trigger Tool for Measuring Adverse Events; Institute for Healthcare Improvement: Cambridge, MA, USA, 2009.

7. Holloway, R.G.; Tuttle, D.; Baird, T.; Skelton, W.K. The safety of hospital stroke care. Neurology 2007, 68, 550-555. [CrossRef]

8. Fernandez-Gotico, H.; Lightfoot, T.; Meighan, M. Multicenter Study of Adverse Events after Intravenous Tissue-Type Plasminogen Activator Treatment of Acute Ischemic Stroke. J. Neurosci. Nurs. 2017, 49, 31-36. [CrossRef]

9. Reason, J. Human error: Models and management. BMJ (Clin. Res. Ed.) 2000, 320, 768-770. [CrossRef]

10. Braithwaite, J.; Wears, R.L.; Hollnagel, E. Resilient health care: Turning patient safety on its head. Int. J. Qual. Health Care J. Int. Soc. Qual. Health Care 2015, 27, 418-420. [CrossRef]

11. WHO. Conceptual Framework for the International Classification for Patient Safety; World Health Organization: Geneva, Switzerland, 2009. 
12. Lindblad, M.; Unbeck, M.; Nilsson, L.; Schildmeijer, K.; Ekstedt, M. Identifying no-harm incidents in home healthcare: A cohort study using trigger tool methodology. BMC Health Serv. Res. 2020, 20, 289. [CrossRef]

13. Schildmeijer, K.; Unbeck, M.; Muren, O.; Perk, J.; Pukk Harenstam, K.; Nilsson, L. Retrospective record review in proactive patient safety work-identification of no-harm incidents. BMC Health Serv. Res. 2013, 13, 282. [CrossRef]

14. Classen, D.C.; Resar, R.; Griffin, F.; Federico, F.; Frankel, T.; Kimmel, N.; Whittington, J.C.; Frankel, A.; Seger, A.; James, B.C. 'Global trigger tool' shows that adverse events in hospitals may be ten times greater than previously measured. Health Aff. (Proj. Hope) 2011, 30, 581-589. [CrossRef] [PubMed]

15. Hibbert, P.D.; Molloy, C.J.; Hooper, T.D.; Wiles, L.K.; Runciman, W.B.; Lachman, P.; Muething, S.E.; Braithwaite, J. The application of the Global Trigger Tool: A systematic review. Int. J. Qual. Health Care 2016, 28, 640-649. [CrossRef] [PubMed]

16. Hwang, J.I.; Chin, H.J.; Chang, Y.S. Characteristics associated with the occurrence of adverse events: A retrospective medical record review using the Global Trigger Tool in a fully digitalized tertiary teaching hospital in Korea. J. Eval. Clin. Pract. 2014, 20, 27-35. [CrossRef]

17. Kurutkan, M.N.; Usta, E.; Orhan, F.; Simsekler, M.C. Application of the IHI Global Trigger Tool in measuring the adverse event rate in a Turkish healthcare setting. Int. J. Risk Saf. Med. 2015, 27, 11-21. [CrossRef]

18. Grossmann, N.; Gratwohl, F.; Musy, S.N.; Nielen, N.M.; Donzé, J.; Simon, M. Describing adverse events in medical inpatients using the Global Trigger Tool. Swiss Med. Wkly. 2019, 149, w20149. [CrossRef] [PubMed]

19. Hommel, A.; Magnéli, M.; Samuelsson, B.; Schildmeijer, K.; Sjöstrand, D.; Göransson, K.E.; Unbeck, M. Exploring the incidence and nature of nursing-sensitive orthopaedic adverse events: A multicenter cohort study using Global Trigger Tool. Int. J. Nurs. Stud. 2020, 102, 103473. [CrossRef] [PubMed]

20. Mattsson, T.O.; Knudsen, J.L.; Brixen, K.; Herrstedt, J. Does adding an appended oncology module to the Global Trigger Tool increase its value? Int. J. Qual. Health Care J. Int. Soc. Qual. Health Care 2014, 26, 553-560. [CrossRef]

21. Gerber, A.; Da Silva Lopes, A.; Szüts, N.; Simon, M.; Ribordy-Baudat, V.; Ebneter, A.; Perrinjaquet, C.; Gaignard, M.E.; Nicodet, D.; Betticher, D.; et al. Describing adverse events in Swiss hospitalized oncology patients using the Global Trigger Tool. Health Sci. Rep. 2020, 3, e160. [CrossRef]

22. Unbeck, M.; Lindemalm, S.; Nydert, P.; Ygge, B.M.; Nylen, U.; Berglund, C.; Harenstam, K.P. Validation of triggers and development of a pediatric trigger tool to identify adverse events. BMC Health Serv. Res. 2014, 14, 655. [CrossRef]

23. Paranaguá, T.T.D.B.; Bezerra, A.L.Q.; Silva, A.E.B.D.C.; Azevedo Filho, F.M.D. Prevalence of no harm incidents and adverse events in a surgical clinic. Acta Paul. Enferm. 2013, 26, 256-262. [CrossRef]

24. Lindblad, M.; Schildmeijer, K.; Nilsson, L.; Ekstedt, M.; Unbeck, M. Development of a trigger tool to identify adverse events and no-harm incidents that affect patients admitted to home healthcare. BMJ Qual. Saf. 2018, 27, 502-511. [CrossRef] [PubMed]

25. Team, R. RStudio: Integrated Development for R. RStudio. Available online: http://www.rstudio.com/ (accessed on 12 May 2019).

26. Swedish Ministry of Health and Social Welfare. Patient Safety Act, (In Swedish: Patientsäkerhetslagen SFS 2010:659). Available online: https: / www.riksdagen.se/sv/dokument-lagar/dokument/svensk-forfattningssamling/patientsakerhetslag-201065 9_sfs-2010-659 (accessed on 2 May 2020).

27. Schildmeijer, K.G.I.; Unbeck, M.; Ekstedt, M.; Lindblad, M.; Nilsson, L. Adverse events in patients in home healthcare: A retrospective record review using trigger tool methodology. BMJ Open 2018, 8, e019267. [CrossRef]

28. Hartwig, S.; Denger, S.; Schneider, P. Severity-Indexed, Incident Report-Based Medication Error-Reporting Program. Am. J. Hosp. Pharm. 1992, 48, 2611-2616. [CrossRef]

29. Bonati, L.; Baumgartner, R.W.; Bonvin, C.; Cereda, C.; Kägi, G.; Luft, A.; Michel, P.; Sztajzel, R.; Nedeltchev, K.; Arnold, M. Ein Werkzeug für die Qualitätssicherung und Forschung. Schweiz. Med.-Forum 2016, 16, 168-169. [CrossRef]

30. Rankin, J. Cerebral vascular accidents in patients over the age of 60. II. Prognosis. Scott. Med. J. 1957, 2, 200-215. [CrossRef] [PubMed]

31. Banks, J.L.; Marotta, C.A. Outcomes validity and reliability of the modified Rankin scale: Implications for stroke clinical trials: A literature review and synthesis. Stroke 2007, 38, 1091-1096. [CrossRef] [PubMed]

32. Microsoft. Excel Office 365 MSO ProPlus. Available online: https:/ / products.office.com/de-de/excel (accessed on 5 May 2019).

33. Panagioti, M.; Khan, K.; Keers, R.N.; Abuzour, A.; Phipps, D.; Kontopantelis, E.; Bower, P.; Campbell, S.; Haneef, R.; Avery, A.J.; et al. Prevalence, severity, and nature of preventable patient harm across medical care settings: Systematic review and meta-analysis. BMJ (Clin. Res. Ed.) 2019, 366, 14185. [CrossRef]

34. Hemphill, J.C.; Bonovich, D.C.; Besmertis, L.; Manley, G.T.; Johnston, S.C. The ICH Score. Stroke 2001, 32, 891-897. [CrossRef]

35. Thomas, E.J.; Petersen, L.A. Measuring errors and adverse events in health care. J. Gen. Intern. Med. 2003, 18, 61-67. [CrossRef]

36. Institute for Healthcare Improvement. IHI Global Trigger Tool Training Resources. Available online: http://www.ihi.org/ resources/Pages/Tools/IHIGlobalTriggerToolTrainingResources.aspx (accessed on 23 June 2018).

37. Unbeck, M.; Schildmeijer, K.; Henriksson, P.; Jürgensen, U.; Muren, O.; Nilsson, L.; Pukk Härenstam, K. Is detection of adverse events affected by record review methodology? an evaluation of the "Harvard Medical Practice Study" method and the "Global Trigger Tool". Patient Saf. Surg. 2013, 7, 10. [CrossRef] 